\title{
DMPK mRNA Expression in Human Brain Tissue Throughout the Lifespan
}

Kathleen E. Langbehn, BA, Zoe Carlson-Stadler, BS, Ellen van der Plas, PhD, Marco M. Hefti, MD, Jeffrey D. Dawson, ScD, David J. Moser, PhD, and Peggy C. Nopoulos, MD

Neurol Genet 2021;7:e537. doi:10.1212/NXG.0000000000000537

\section{Abstract}

\section{Objective}

Myotonic dystrophy is a multisystem disorder caused by a trinucleotide repeat expansion on the myotonic dystrophy protein kinase (DMPK) gene. To determine whether wildtype DMPK expression patterns vary as a function of age, we analyzed DMPK expression in the brain from 99 donors ranging from 5 postconceptional weeks to 80 years old.

\section{Methods}

We used the BrainSpan messenger RNA sequencing and the Yale Microarray data sets, which included brain tissue samples from 42 and 57 donors, respectively. Collectively, donors ranged in age from 5 postconceptional weeks to 80 years old. DMPK expression was normalized for each donor across regions available in both data sets. Restricted cubic spline linear regression models were used to analyze the effects of log-transformed age and sex on normalized DMPK expression data.

\section{Results}

Age was a statistically significant predictor of normalized DMPK expression pattern in the human brain in the BrainSpan $(p<0.005)$ and Yale data sets $(p<0.005)$. Sex was not a significant predictor. Across both data sets, normalized wildtype DMPK expression steadily increases during fetal development, peaks around birth, and then declines to reach a nadir around age 10 .

\section{Conclusions}

Peak expression of $D M P K$ coincides with a time of dynamic brain development. Abnormal brain DMPK expression due to myotonic dystrophy may have implications for early brain development.
Correspondence

Dr. Nopoulos

peggy-nopoulos@uiowa.edu

From the Department of Psychiatry (K.E.L., Z.C.-S., E.v.d.P., D.J.M., and P.C.N.), Department of Pathology (M.M.H.), Department of Pediatrics (P.C.N.), and Department of Neurology (P.C.N.), College of Public Health (J.D.D.), University of lowa. 


\section{Glossary}

AD = Alzheimer disease AIC = Akaike information criterion; DM1 = myotonic dystrophy type $1 ; \mathbf{D M P K}=$ myotonic dystrophy protein kinase; GEO = Gene Expression Omnibus; ICV = intracranial volume; $\mathbf{M B N L}=$ muscle-blind like; $\mathbf{m R N A}=$ messenger RNA; miRNA = microRNA; NCBI = National Center for Biotechnology Information; NFT = neurofibrillary tangle; $\mathbf{P C W}=$ postconceptional week; RAN = repeat-associated non-adenine-thymine-guanine; $\mathbf{R C S}=$ restricted cubic spline.

Myotonic dystrophy type 1 (DM1) is a degenerative muscular disorder caused by a mutation of the trinucleotide expansion on the $3^{\prime}$ untranslated region of the dystrophia myotonica protein kinase (DMPK) gene on chromosome 19, where DM1 is associated with 50 or more cytosine-thymine-guanine (CTG) repeats. ${ }^{1}$ The DMPK gene codes for the myotonic dystrophy protein kinase (DMPK). Lower levels of DMPK were found in skeletal and cardiac muscles of patients with DM1 (OMIM 605377; https://www.omim.org/entry/605377). ${ }^{2}$ In situ hybridization analysis showed that DMPK messenger RNA (mRNA) is expressed in a range of adult mouse tissues, including the brain. ${ }^{3}$ DMPK has been implicated in maintaining cytoarchitecture of skeletal and smooth muscles and intracellular trafficking (e.g., $\mathrm{Ca}^{2+}$ cycling and ion-channel gating). ${ }^{4}$ The autosomal-dominant CTG expansion causing DM1 is present from conception, ${ }^{5}$ and pathophysiology may start then as well.

Genetic anticipation can dramatically increase the number of CTG repeats into extreme ranges in which the disease manifests at birth (congenital) or early life (childhood onset). In these phenotypes, the primary morbidity is intellectual disability rather than muscle dysfunction, suggesting that the mutated gene has direct effects on the brain. ${ }^{6}$ Lower IQ scores and cognitive difficulties have also been noted in individuals with adult-onset $\mathrm{DM} 1 .{ }^{7,8}$ Moreover, neuroimaging studies have documented substantial reductions in regional brain volume ${ }^{6}$ and white matter fractional anisotropy. ${ }^{8}$ CNS impairment in DM1 are believed to be the result mutant DMPK mRNA. ${ }^{9}$

To understand how abnormal expression of a gene may lead to pathogenesis, it is crucial to first understand the mechanism of normal genetic expression. Thus, evaluation of wildtype DMPK expression in the brain across the lifespan would offer insight into the role of DMPK in neurodevelopment and would generate hypotheses about the potential effects of mutant DMPK. Accordingly, the aim of the present study was to evaluate the lifetime trajectory of normal DMPK expression in the brains of unaffected individuals, using existing resources provided by BrainSpan: Atlas of the Developing Human Brain and the Yale Microarray Database. Reflecting its important role, we hypothesized that levels of DMPK expression in brain tissue would be higher during dynamic phases of neurodevelopment.

\section{Methods}

To assess the normal global expression of the DMPK gene in brain tissue across the human lifespan, 2 publicly available, independent, data sets were used-BrainSpan (42 healthy patients across 16 developed brain regions and 10 developing areas of neocortex) and Yale Human Brain Transcriptome (57 healthy patients across 16 developed brain regions and 11 developing areas of neocortex). Samples ranged from the early fetal period (5-19 weeks postconception) through late adult (80+ years).

\section{Brainspan}

In the BrainSpan data set, RNA sequencing was used to explore of the entire transcriptome without a priori assumptions. Tissue samples from 42 donors were used (age range: 5 postconceptional weeks [PCWs] to 40 years old). Ten immature brain regions were sampled from donors aged 4-9 PCW, and 16 brain regions were sampled from donors aged $\geq 10$ PWC. No prenatal and neonatal brains with evidence of maternal drug or alcohol abuse were used nor were brains from donors who had signs of brain lesions or malformations. Detailed methods were previously described ${ }^{10}$ and can be found in Technical white paper: Transcriptome profile by RNA sequencing and exon microarray (October 2013; brainspan.org/).

\section{Yale Human Brain Transcriptome}

In the Yale Human Brain Transcriptome data set, whole genome microarray was used to explore the entire human brain transcriptome. The tissue samples in this experiment came from 57 donors (age range: 5.7 PCW to 82 years old) and had been identified as "clinically unremarkable" with no signs of genetic abnormalities identified during genotyping. From these donors, tissue was collected across 16 mature postnatal brain regions and 11 regions of immature embryonic and early fetal neocortex. Detailed methods have been previously described, ${ }^{11}$ and the Yale Microarray RNA-sequencing data for this analysis was accessed from the National Center for Biotechnology Information (NCBI) Gene Expression Omnibus (GEO; GEO accession number GSE25219; ncbi.nlm.nih.gov/geo).

\section{Sample}

After limiting analyses to the 25 brain regions in both data sets, the BrainSpan data set consisted of mRNA data collected from 42 unique donors from 26 brain regions with a median of 14 samples per donor (range 1-16). The Yale Human Brain Transcriptome data set included microarray data collected from 57 unique donors via 14 probes in 27 brain regions with a median of 16 samples per donor (range 2-16). Within each individual donor, there was little $D M P K$ expression variation between brain regions (figure 1), therefore, we evaluated the overall gene expression. 


\section{Standard Protocol Approvals, Registrations, and Patient Consents}

\section{BrainSpan RNA Seq Data}

All work was performed according to guidelines for the research use of human brain tissue with approval of each samples institute; appropriate written informed consent was obtained, and nonidentifying information was recorded for each sample. ${ }^{10}$

\section{Yale Microarray Data}

All human subject data that are a part of the NCBI GEO database are in accord with the original consent, including permission to submit the data to a public database, from individual institution IRBs and are in accord with all applicable laws, regulations, and institutional policies (GEO accession number GSE25219; ncbi.nlm.nih.gov/geo).

\section{Statistical Approach}

The dependent variable in all models was normalized DMPK expression across all brain tissues shared across both databases. First, both the BrainSpan and Yale data were limited to brain regions available in both samples, which required removal of samples from 1 region in the BrainSpan data (cerebellum) and 3 regions in the Yale data (diencephalon, ventral forebrain, and frontal cerebral wall) resulting in 25 overlapping regions. Second, we transformed age to postconceptional weeks (PCWs), then log-transformed PCW for comparability. For descriptive purposes, we also divided PCW into intervals (table 1). Transcriptome-wide RNA sequencing data from the BrainSpan data set were averaged across available regions for each donor to create a normalized DMPK variable per individual because each donor did not have the same number of regions sampled. Microarray data from the Yale data set were normalized across 14 probes in each brain region and summed to create one global normalized $D M P K$ variable per individual.

Our objective was to determine whether global normalized $D M P K$ expression in the human brain varied as a function of age (predictor variable). The impact of sex on normalized $D M P K$ was explored, and this predictor was retained in the models only if it had a significant impact on DMPK expression $(p<0.05)$. Nonlinear component significance of logtransformed age, coefficient estimates, and $95 \%$ confidence intervals were calculated for each cubic spline knot.

In exploratory analyses, LOESS curves were fitted to the observed data to explore nonlinear age trends and to select cubic spline framework. Restricted cubic spline (RCS) analyses were implemented to identify nonlinear age-related change in DMPK expression. Akaike information criterion (AIC) was used to determine models with the highest quality fit to the data from both data sets.

All analyses were completed using RStudio version 1.2.5042. ${ }^{12}$ We used ggplot2 for data visualization, ${ }^{13}$ the package rsm for running RCSs, ${ }^{14}$ and we used the effect size package to calculate effect sizes. ${ }^{15}$

\section{Data Availability}

BrainSpan RNA sequencing data are publicly available via BrainSpan Atlas of the Developing Human Brain (2010); Yale Microarray data are publicly available via the NCBI GEO (GEO accession number GSE25219; ncbi.nlm.nih.gov/geo).

\section{Results}

\section{Sample Description}

The BrainSpan data set consisted of mRNA data collected from 42 unique donors from 26 brain regions with a median of 14 samples per donor (range 1-16). The Yale Human Brain Transcriptome data set included microarray data collected from 57 unique donors via 14 probes in 27 brain regions with a median of 16 samples per donor (range 2-16). Within each individual donor, there was little DMPK expression variation between brain regions (figure 1); therefore, we evaluated overall gene expression. BrainSpan samples ranged from early fetal to middle adult donors ( 8 PCW to 40 years), and Yale samples ranged from early fetal to late adult donors (5.7 PCW to 82 years).

\section{DMPK Expression}

AIC determined that a parsimonious model could be achieved from a cubic model predicting normalized DMPK expression's association with log-transformed age (table e-1, links. lww.com/NXG/A346). Sex did not have a significant impact of DMPK expression for either the BrainSpan data set $(F(1,37)=2.32, p=0.136)$ or the Yale data set $(F(1,52)=$ $3.74, p=0.064)$.

The nonlinear components of log-transformed PCW in the human brain in both data sets were a highly significant predictor of normalized DMPK expression pattern in the human brain across both data sets $-F(2,878.98)=7.95, p=0.0013$; $F(2,3.03)=11.70, p=6.21 \mathrm{e}^{-05}$, respectively. Coefficient estimates and $95 \%$ confidence intervals for each cubic spline knots are shown for BrainSpan (table 2) and Yale (table 3). As can be seen in figure 2 , the model shows that the mean DMPK expression steeply increased in the prenatal period, peaked near the time of birth, and declined for the first 10 years postpartum, either leveling off or increasing after that.

\section{Post Hoc Analyses}

To obtain further insight to the observed trends, we divided the data into strata of $<10$ and $\geq 10$ years old and repeated our analyses within strata. The nonlinear components of logtransformed PCW in both BrainSpan and Yale donors $<10$ years old were highly significant: $F(3,998.6)=4.96, p=0.007$; $F(4,2.06)=2.06, p=0.0006$, respectively. In donors over 10 years old, the nonlinear component of log-transformed PCW was not significant in either BrainSpan or Yale donors- 
A. BrainSpan
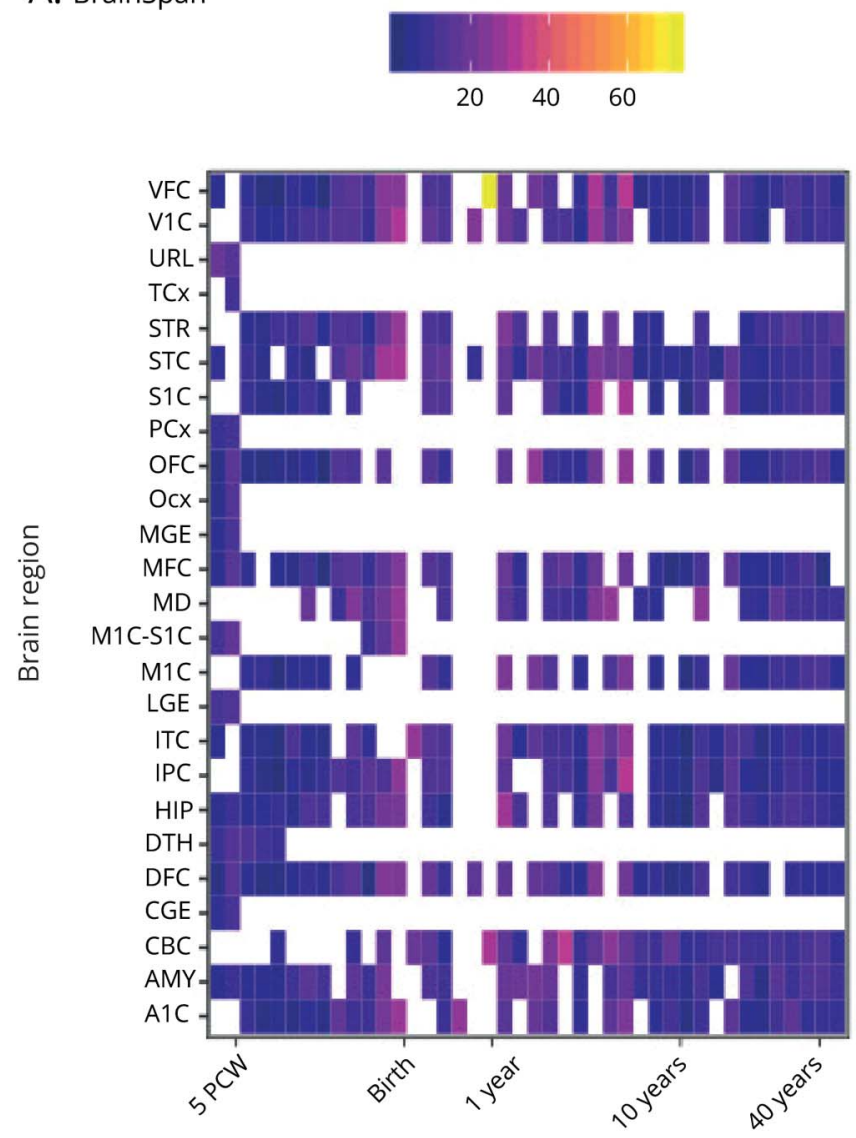

Donor (ordered by age)
B. Yale
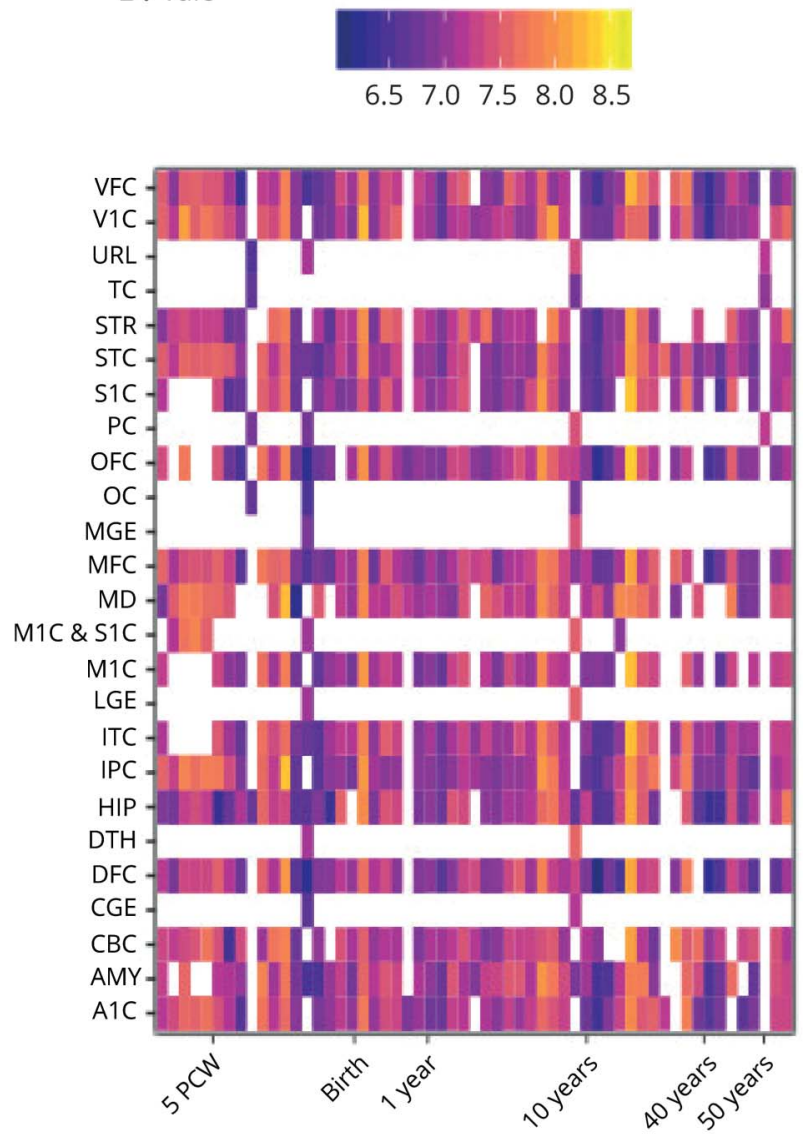

Donor (ordered by age)

DMPK expression levels for each brain tissue region sampled (y-axis) across donors ordered by ascending age (x-axis). Cool and darker colors indicate lower DMPK expression levels; warm and lighter colors indicate higher DMPK expression levels. Note that white squares represent instances where no expression data were available for that region at that particular age. Panel A shows the BrainSpan RNA-sequencing data; panel B shows the Yale Microarray data. DMPK= myotonic dystrophy protein kinase; PCW = postconceptional week.

$F(3,43.64)=1.61, p=0.28 ; F(1,0.06)=0.98, p=0.33$, respectively.

Furthermore, these analyses still showed a peak around birth, confirming that the peak fit by the spline was not an artifact driven by subjects $\geq 10$ years. In the older strata ( $\geq 10$ years), age was not a significant predictor of $D M P K$ expression pattern in either data sets, suggesting that the slight increase in $D M P K$ expression after age 10 is an artifact of the model fit; rather, $D M P K$ expression levels off with age. Noting that only the Yale data set had samples from donors older than the age of 40 years, we did not deem it feasible to properly examine $D M P K$ expression to draw generalizable conclusions from such a small sample.

In the BrainSpan data set, one donor was identified as a potential outlier because of their high DMPK expression value. We ran analyses with and without that donor's samples, and the results remained robust after removing; thus, we concluded that our results were not driven by this elevated raw
$D M P K$ expression value and kept those samples in our data (table e-2, links.lww.com/NXG/A347).

\section{Discussion}

We examined DMPK expression patterns in global brain tissue over the human lifespan. Age-related change of wildtype $D M P K$ expression in the human brain was characterized by steady increase from the early PCWs until shortly after birth, followed by a decline in childhood and throughout middle adulthood (approximately 40 years old). This pattern was observed across 2 independent data sets using different methods of DMPK expression quantification using multiple data sets with unique samples increases our confidence with interpreting such developmental trajectories. ${ }^{16} \mathrm{DMPK}$ expression exhibits a clear postnatal peak during a period marked by dynamic brain developmental changes influenced by both genetic and environmental factors. Although the most rapid neurodevelopmental changes during the lifespan occur 
Table 1 Sample Description

\begin{tabular}{|c|c|c|c|c|c|}
\hline \multirow[b]{2}{*}{ Age } & \multirow[b]{2}{*}{ Description } & \multicolumn{2}{|c|}{ No. of individuals } & \multicolumn{2}{|c|}{ No. of samples } \\
\hline & & BrainSpan & Yale & BrainSpan & Yale \\
\hline <19 PCW & Early-fetal & 13 & 14 & 180 & 340 \\
\hline$\leq 19$ age $<38$ PCW & Late-fetal & 7 & 10 & 54 & 251 \\
\hline Birth < 12 mo & Infancy & 5 & 6 & 59 & 139 \\
\hline $1 \leq$ age $<6 y$ & Childhood & 4 & 4 & 44 & 69 \\
\hline $6 \leq$ age $<20 y$ & Adolescence & 7 & 7 & 91 & 129 \\
\hline $20 \leq$ age $<40 y$ & Young-adult & 5 & 9 & 78 & 220 \\
\hline $40 \leq$ age $<60 y$ & Middle-adult & 1 & 4 & 15 & 91 \\
\hline $60 y \leq$ age & Late-adult & - & 3 & - & 93 \\
\hline
\end{tabular}

Abbreviation: PCW = post-conceptional week.

during the prenatal period, the brain continues to change dramatically postnatally as well, including the doubling of cerebral volume within the first year of life. ${ }^{17,18}$ Elevated levels of DMPK during development would indicate high levels of abnormally expanded DMPK in mutation carriers. This would in turn amplify disruption of normal expression and splicing because of sequestration of transcription and splicing factors by DMPK during development. Arguably, the expression of mutant DMPK during critical periods of neurodevelopment could lead to neurodevelopmental disorders such as the ubiquitous and often severe intellectual disability observed in those with early onset DM1. ${ }^{7}$

It is important that brain development is a very prolonged process. For instance, intracranial volume (ICV) is determined almost exclusively by maximum brain growth and peaks around midadolescence. ${ }^{18}$ Thus, although wildtype $D M P K$ expression decreases substantially by roughly age 10 , its effects on early processes are likely to impact the trajectories of events that occur later. This means that the impact of a mutant gene on brain development that ultimately manifests as smaller ICV is likely because of a disruption of events that occur long before adolescence. Given the high expression of $D M P K$ during the first 12 months of life, DMPK could affect the process of maximal brain growth. Furthermore, maximal brain growth is simply a litmus test indicating developmental aberration and says nothing about the processes and events that may be affecting specific tissues and circuitry; however, the neurobiology of early onset DM1 in humans has not been studied enough to support hypotheses regarding specific disruptions in this disease.

The pathogenic mechanisms of mutant DMPK that manifest in DM1 are believed to be because in part of toxic RNAinduced splicing misregulation. Mutant RNA interferes with the role of muscle-blind-like proteins (MBNL) in alternate splicing modulation, resulting in what is termed a "spliceopathy."19-21 Charizanis et al. ${ }^{20}$ showed that loss of MBNL2 protein in mice led to widespread splicing abnormalities in brain tissue, whereas MBNL1 knockout mice showed these abnormalities in skeletal muscle tissue. In adult DM1 tissues, Kuyumcu-Martinez and Cooper ${ }^{21}$ noted embryonic and fetal splicing patterns that indicated these tissues had not undergone the normal pre-mRNA wildtype developmentally regulated splicing switch. These findings indicate that disruption of the regulation of alternative splicing causes normal mRNA variants to be expressed in inappropriate tissues and developmental stages. Another pathogenic mechanism of DM1 is decreased expression of DMPK protein. ${ }^{22}$ As shown in the current study, wildtype DMPK expression has a clear age-related pattern; however, it is unknown whether similar age-related patterns occur in individuals with DM1. It is possible that DMPK expression is consistently low in DM1 patients, but it may be the case that DM1 patients exhibit abnormal age-related changes in DMPK expression.

A further consideration is the impact of repeat-associated non-adenine-thymine-guanine (RAN) translation, where microsatellite expansions cause disruptions in translation initiation that generates unexpected repeat proteins. ${ }^{23} \mathrm{Un}$ derstanding expression patterns of these RAN proteins in brain tissue of DM1 patients could lead to a better understanding of the basic mechanisms of this disease.

Beyond MBNL, another neurodevelopmental protein that is often abnormally expressed in DM1 is Tau, which is required for polymerization and stability of microtubules. When Tau is mis-spliced, it results in neurofibrillary tangles (NFTs) in the brain which affect behavioral and cognitive function. ${ }^{21,24}$ The neurodegenerative diseases resulting from NFT build-ups are known as a "tauopathies," such as Alzheimer disease (AD) and frontotemporal dementia. Mis-splicing of Tau was first noted in a study that included brain tissue of $2 \mathrm{DM} 1$ patients that 
Table 2 BrainSpan RCS Model of DMPK Expression Over Time BrainSpan DMPK Expression

\begin{tabular}{llll}
\hline Predictors & Estimates & Cl & $p$ Value \\
\hline Intercept & -32.65 & -59.27 to -6.04 & 0.018 \\
\hline $\log$ (age.pcw) & 16.93 & 7.44 to 26.43 & 0.001 \\
\hline $\log$ (age.pcw)' & -127.89 & -206.77 to -49.00 & 0.002 \\
\hline $\log$ (age.pcw) $)^{\prime \prime}$ & 174.43 & 62.51 to 286.35 & 0.003 \\
\hline
\end{tabular}

Abbreviations: $\mathrm{Cl}=$ confidence interval; $\mathrm{DMPK}=$ myotonic dystrophy protein kinase; $\mathrm{PCW}=$ postconceptional week; $\mathrm{RCS}=$ restricted cubic spline.

Log(age), log(age )', and log(age)" refer to cubic spline transformations of log-transformed age in PCWs. RCS knots are at 2.484907, 3.091258, 5.278115, and 7.119636 (5th, 35th, 65th, and 95th percentiles of log[PCW]). Individual spline terms are not easily interpreted for statistical significance or the meaning of their estimated coefficients. Rather, the estimated, flexible nonlinearity is clearly illustrated in figure 2. See text for joint significance of log(PCW) effects.

was compared with tau profiles in brains of $\mathrm{AD}$ patients. ${ }^{25} \mathrm{In}$ contrast to the $\mathrm{AD}$ brains, no amyloid deposition was detected in brains of DM1 patients, suggesting differential tauopathies. Alternative splicing of Tau has also been reported postnatally in DM1. In a recent review, Fernandez-Gomez et al. ${ }^{26}$ noted that although Tau mRNA alternative splicing is generally firmly regulated, the somatic instability of the DM1 mutation causes a reversal of these splicing patterns such that fetal patterns of Tau are expressed in adult tissues. Additional studies have also shown that fetal forms of Tau were expressed in adult brain tissue in individuals with DM1, following the same pattern of misregulated expression as MBNL proteins. ${ }^{27}$ Noting this fetal-type pattern of misregulated alternative splicing in Tau, coupled with toxic RNA sequestration of MBNL proteins in DM1, we postulate that characterizing $D M P K$ protein expression patterns throughout the lifespan may help further clarify the developmental mechanisms of DM1.

MicroRNAs (miRNAs) play important roles in neurodevelopmental, neurodegenerative, and neuropsychiatric diseases and are involved in the maintenance of human embryonic stem cell, a subset of which affect neural development and show highest concentrations localized in the cerebral cortex and cerebellum. ${ }^{19}$ Specific miRNAs show increased levels of expression of formative neurodevelopmental proteins (e.g., MBNL, Tau) during progressive stages of cortical development that may be affected by different miRNA-associated polymorphisms. Predicted miRNA targets for such polymorphisms include proteins involved in neurodevelopmental and neurodegenerative diseases and thus may be the mechanism for emergence of these diseases. CTG-repeat binding miRNAs (e.g., mir-107 and mir-103), which are strongly expressed in the brain, were found to preferentially bind to DMPK transcript in a length-dependent manner. ${ }^{28}$ This suggests that CTG-repeat binding miRNA could result in alterations of DMPK expression in the brain. Wang et al. ${ }^{27}$ reported reduced MBNL1 and MBNL2 in mice with postnatal expression patterns of expanded CUG RNA compared with controls, showing that similar abnormal MBNL-regulated splicing can be seen in DM1 brains across species. These results of decreased synaptic function before degeneration of axons and dendrites fit previous models of neurodegenerative diseases and may provide pathologic evidence for brain atrophy in DM1.

In DM1, there is a dose effect of CTG repeats such that higher repeats lead to earlier onset. Although onset of DM1 early in life is associated with clear developmental aberration, whether there is any component of abnormal development in classical adult onset DM1 has not been thoroughly investigated. The DM1 mutation results in decreased levels of DMPK protein, approximately half that of unaffected expression levels in mouse models of human $D M P K,{ }^{29}$ and symptom onset may be the result of critically

Table 3 Yale Microarray RCS Model DMPK Expression Yale Microarray DMPK Expression

\begin{tabular}{|c|c|c|c|}
\hline Predictors & Estimates & $\mathrm{Cl}$ & $p$ Value \\
\hline Intercept & 5.37 & 4.54 to 6.20 & $<0.001$ \\
\hline log(age.pcw) & 0.68 & 0.38 to 0.97 & $<0.001$ \\
\hline log(age.pcw)' & -5.50 & -8.05 to -2.95 & $<0.001$ \\
\hline log(age.pcw)" & 6.97 & 3.65 to 10.29 & $<0.001$ \\
\hline
\end{tabular}

Abbreviations: $\mathrm{Cl}$ = confidence interval; DMPK = myotonic dystrophy protein kinase; PCW = postconceptional week; RCS = restricted cubic spline Log(age), log(age)', and log(age)" refer to cubic spline transformations of log-transformed age in PCWs. RCS knots are at 6.661885, 6.930415, 7.273223, and 7.822536 (5th, 35th, 65th, and 95th percentiles of log[PCW]). Individual spline terms are not easily interpreted for statistical significance or the meaning of their estimated coefficients. Rather, the estimated, flexible nonlinearity is clearly illustrated in figure 2 . See text for joint significance of log(PCW) effects. 


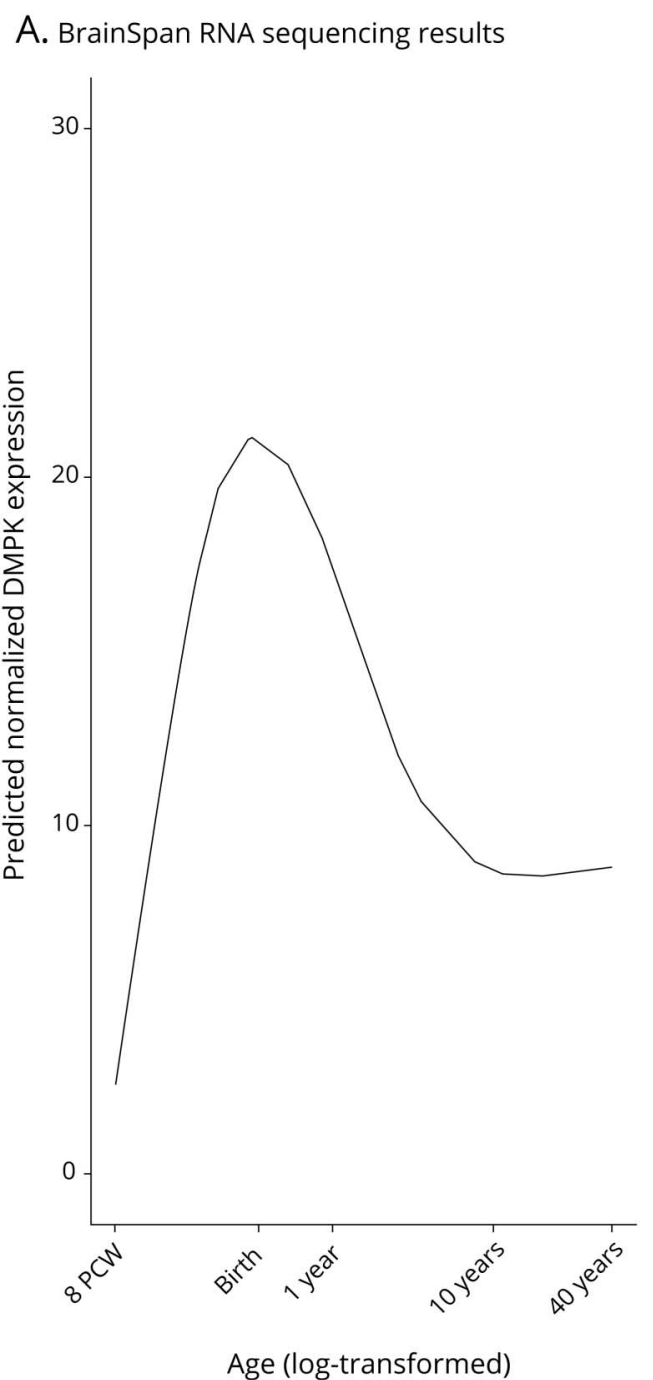

B. Yale microarray results

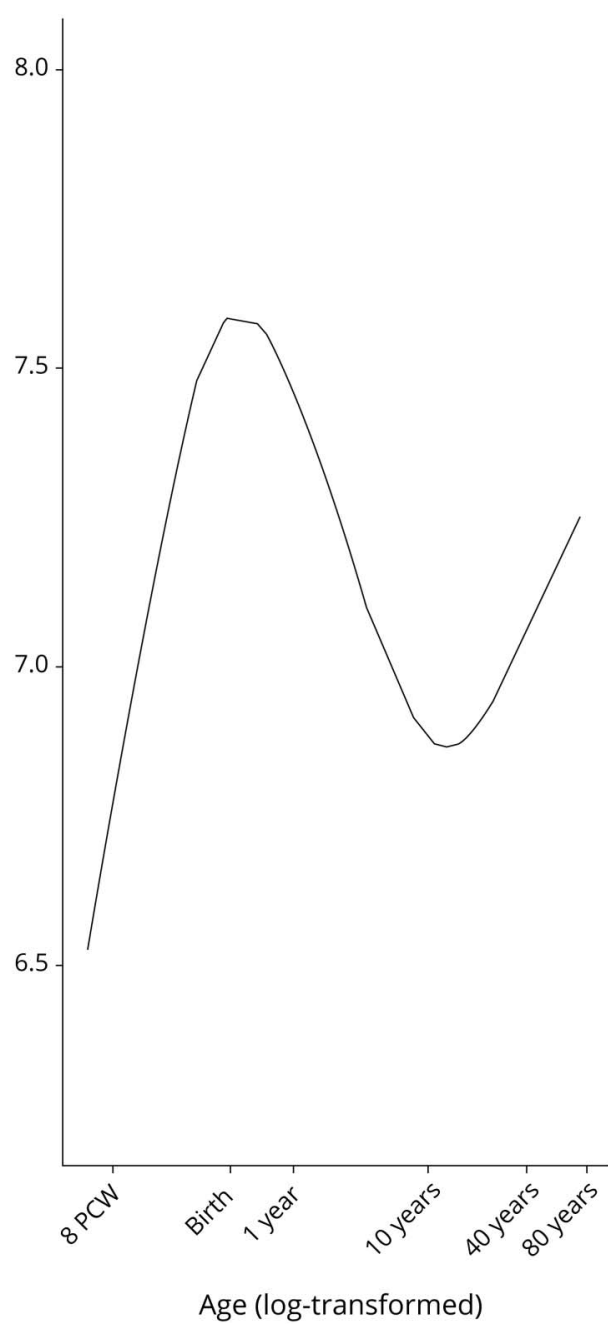

Fitted values for normalized DMPK expression (y-axis) in the human brain throughout the lifespan ( $\mathrm{x}$ axis). The curves represent the fitted values derived from restricted cubic spline model with normalized DMPK expression was predicted by age. Panel A (left) shows results from Brainspan database messenger RNA sequencing method; panel B (right) shows results from Yale database microarray method. $D M P K=$ myotonic dystrophy protein kinase; $\mathrm{PCW}=$ postconceptional week. low amounts of DMPK transcripts and protein. ${ }^{30}$ It is unknown whether the trajectory of DMPK expression differs in DM1 patients from unaffected individuals. Two neuroimaging studies in DM1 patients have reported indirect evidence of a neurodevelopmental component in adult onset DM1. Our own group showed that ICV was significantly smaller in DM1 patients relative to controls, ${ }^{6}$ suggesting some component of developmental aberration in this cohort of patients. Others reported lower white matter volume in DM1 patients compared with unaffected adults, not attributable to aging. ${ }^{31}$ In the absence of clear aging-related factors contributing to reduced white matter, the authors postulated that the difference may be of a neurodevelopmental nature. It may be appropriate to conceptualize developmental aberrations across phenotypic variants of DM1 as a continuum; although the developmental aberrations is most pronounced in congenital DM1, even the adult-onset phenotype can be associated with some degree of developmental aberration.
We leveraged existing data to explore brain DMPK expression throughout the human lifespan. In doing so, we had limited control over collection of donor tissues. The BrainSpan data set consisted of donors through age 40, limiting our ability to make inferences about DMPK expression later in life. Sampling bias may contribute to differential availability of donor tissue across ages.

Future research in the field of brain tissue expression patterns should be conducted in participants with DM1 to characterize expression patterns of mutant $D M P K$ in individuals with DM1. Considering that motor manifestations of DM1 most typically appear in adulthood, we may expect to see an increase in DMPK expression later in life. An additional focus may be the impact of CTG repeat length on mutant DMPK expression in patients with DM1. Further studies in DM1 and other trinucleotide repeat neurodegenerative diseases may benefit from additional pathogenetic research into both wildtype and mutant protein expressions. 
The prenatal period and the first year of life mark a time of rapid changes in brain development. This critical period in brain development coincides with a peak in DMPK expression in the brain. The severe mutation of the DMPK gene affects brain volume in the juvenile onset form of DM1, and individuals with adult-onset DM1 exhibit abnormal brain structure. ${ }^{6}$ Understanding the normal function of a protein and gene is a key part of discovering what could go wrong if that protein is mutated, thus furthering the understanding of the disease state.

\section{Study Funding}

The authors report no targeted funding.

\section{Disclosure}

The authors report no disclosures relevant to the manuscript. Go to Neurology.org/NG for full disclosures.

\section{Publication History}

Received by Neurology: Genetics April 20, 2020. Accepted in final form October 19, 2020.

\section{Appendix Authors}

\begin{tabular}{|c|c|c|}
\hline Name & Location & Contribution \\
\hline $\begin{array}{l}\text { Kathleen E. } \\
\text { Langbehn, } \\
\text { BA }\end{array}$ & $\begin{array}{l}\text { University of lowa } \\
\text { Hospitals and } \\
\text { Clinics }\end{array}$ & $\begin{array}{l}\text { Analyzed and interpreted the data } \\
\text { and drafted the manuscript for } \\
\text { intellectual content }\end{array}$ \\
\hline $\begin{array}{l}\text { Zoe Carlson- } \\
\text { Stadler, BS }\end{array}$ & $\begin{array}{l}\text { University of lowa } \\
\text { Hospitals and } \\
\text { Clinics }\end{array}$ & $\begin{array}{l}\text { Analyzed and interpreted the data } \\
\text { and drafted the manuscript for } \\
\text { intellectual content }\end{array}$ \\
\hline $\begin{array}{l}\text { Ellen van } \\
\text { der Plas, } \\
\text { PhD }\end{array}$ & $\begin{array}{l}\text { University of lowa } \\
\text { Hospitals and } \\
\text { Clinics }\end{array}$ & $\begin{array}{l}\text { Designed and conceptualized study, } \\
\text { analyzed and interpreted the data, } \\
\text { and drafted and revised the } \\
\text { manuscript for intellectual content }\end{array}$ \\
\hline $\begin{array}{l}\text { Marco M. } \\
\text { Hefti, MD }\end{array}$ & $\begin{array}{l}\text { University of lowa } \\
\text { Hospitals and } \\
\text { Clinics }\end{array}$ & $\begin{array}{l}\text { Designed and conceptualized the } \\
\text { study and revised the manuscript } \\
\text { for intellectual content }\end{array}$ \\
\hline $\begin{array}{l}\text { Jeffrey D. } \\
\text { Dawson, } \\
\text { SCD }\end{array}$ & University of Iowa & $\begin{array}{l}\text { Interpreted the data and revised the } \\
\text { manuscript for intellectual content }\end{array}$ \\
\hline $\begin{array}{l}\text { David J. } \\
\text { Moser, PhD }\end{array}$ & $\begin{array}{l}\text { University of lowa } \\
\text { Hospitals and } \\
\text { Clinics }\end{array}$ & $\begin{array}{l}\text { Revised the manuscript for } \\
\text { intellectual content }\end{array}$ \\
\hline $\begin{array}{l}\text { Peggy C. } \\
\text { Nopoulos, } \\
\text { MD }\end{array}$ & $\begin{array}{l}\text { University of lowa } \\
\text { Hospitals and } \\
\text { Clinics }\end{array}$ & $\begin{array}{l}\text { Designed and conceptualized the } \\
\text { study and revised the manuscript } \\
\text { for intellectual content }\end{array}$ \\
\hline
\end{tabular}

\section{References}

1. Cho DH, Tapscott SJ. Myotonic dystrophy: emerging mechanisms for DM1 and DM2. Biochim Biophys Acta 2007;1772:195-204.

2. Online Mendelian Inheritance in Man, OMIM ${ }^{\ominus}$. Johns Hopkins University, Baltimore, MD. MIM Number: 605377 November 8, 2020. Available at: https://omim. org/. Accessed January 17, 2020.
3. Kaliman P, Llagostera E. Myotonic dystrophy protein kinase (DMPK) and its role in the pathogenesis of myotonic dystrophy 1. Cell Signal 2008;20:1935-1941.

4. O'Cochlain DF, Perez-Terzic C, Reyes S, et al. Transgenic overexpression of human DMPK accumulates into hypertrophic cardiomyopathy, myotonic myophaty and hypotension traits of myotonic dystrophy. Hum Mol Genet 2004; $13: 2505-2518$.

5. Day JW, Ranum LPW. RNA pathogenesis of the myotonic dystrophies. Neuromuscul Disord 2005;15:5-16.

6. Van Der Plas E, Hamilton MJ, Miller JN, et al. Brain structural features of myotonic dystrophy type 1 and their relationship with CTG repeats. J Neuromuscul Dis 2019;6: 321-332.

7. Gourdon G, Meola G. Myotonic dystrophies: state of the art of new therapeutic developments for the CNS. Front Cell Neurosci 2017;11:1-14.

8. Okkersen K, Buskes M, Groenewoud J, et al. The cognitive profile of myotonic dystrophy type 1: a systematic review and meta-analysis. Cortex 2017;95:143-155. doi: 10.1016/j.cortex.2017.08.008.

9. Jiang H, Mankodi A, Swanson MS, Moxley RT, Thornton CA. Myotonic dystrophy type 1 is associated with nuclear foci of mutant RNA, sequestration of muscleblind proteins and deregulated alternative splicing in neurons. Hum Mol Genet 2004;13: 3079-3088.

10. Miller J, Ding S, Sunkin S, et al. Transcriptional landscape of the prenatal human brain. Nature 2014;508:199-206.

11. Kang HJ, Kawasawa YI, Cheng F, et al. Spatiotemporal transcriptome of the human brain. Nature 2013;478:483-489.

12. RStudio Team. RStudio: Integrated Development for R [online]. Boston: RStudio, Inc.; 2020. Available at: rstudio.com/. Accessed January 27, 2020.

13. Wickham H. ggplot2: Elegant Graphics for Data Analysis [online]. 1st ed. New York: Springer-Verlag; 2016. Available at: ggplot2.tidyverse.org. Accessed January 27, 2020.

14. Harrell FE. rms: Regression Modeling Strategies [online]. R Package version 5.1-3.1. 2019. Available at: cran.r-project.org/package $=$ rms. Accessed January 27, 2020.

15. Ben-Shachar M, Makowski D, Lüdecke D. Compute and interpret indices of effect size. CRAN [online serial]. 2020. Available at: github.com/easystats/ effectsize. Accessed January 27, 2020.

16. Mills KL, Goddings AL, Herting MM, et al. Structural brain development between childhood and adulthood: convergence across four longitudinal samples. Neuroimage 2016;141:273-281.

17. Gilmore JH, Shi F, Woolson SL, et al. Longitudinal development of cortical and subcortical gray matter from birth to 2 years. Cereb Cortex 2012;22: 2478-2485.

18. Stiles J, Jernigan TL. The basics of brain development. Neuropsychol Rev 2010;20: 327-348.

19. Mehler MF, Mattick JS. Noncoding RNAs and RNA editing in brain development, functional diversification, and neurological disease. Physiol Rev 2007;87:799-823.

20. Charizanis K, Lee KY, Batra R, et al. Muscleblind-like 2-mediated alternative splicing in the developing brain and dysregulation in myotonic dystrophy. Neuron 2012;75: 437-450.

21. Kuyumcu-Martinez NM, Cooper TA. Misregulation of alternative splicing causes pathogenesis in myotonic dystrophy. Prog Mol Subcell Biol 2006;44:133-159.

22. Souidi A, Zmojdzian M, Jagla K. Dissecting pathogenetic mechanisms and therapeutic strategies in Drosophila models of myotonic dystrophy type 1. Int J Mol Sci 2018;19: 1-14.

23. Cleary JD, Ranum LPW. Repeat-associated non-ATG (RAN) translation in neurological disease. Hum Mol Genet 2013;22:45-51.

24. Buée L, Bussière T, Buée-Scherrer V, Delacourte A, Hof PR. Tau protein isoforms, phosphorylation and role in neurodegenerative disorders. Brain Res Rev 2000;33: 95-130.

25. Vermersch P, Sergeant N, Ruchoux MM, et al. Specific tau variants in the brains of patients with myotonic dystrophy. Neurology 1996;47:711-717.

26. Fernandez-Gomez FJ, Tran H, Dhaenens CM, et al. Myotonic dystrophy: an RNA toxic gain of function tauopathy? In: Tau Biology: Advances in Experimental Medicine and Biology. Singapore: Springer; 2019:207-216. doi: 10.1007/978-981-329358-8.

27. Wang PY, Lin YM, Wang LH, Kuo TY, Cheng SJ, Wang GS. Reduced cytoplasmic MBNL1 is an early event in a brain-specific mouse model of myotonic dystrophy. Hum Mol Genet 2017;26:2247-2257.

28. Hon LS, Zhang Z. The roles of binding site arrangement and combinatorial targeting in microRNA repression of gene expression. Genome Biol 2007;8:1-18.

29. Carrell ST, Carrell EM, Auerbach D, et al. Dmpk gene deletion or antisense knockdown does not compromise cardiac or skeletal muscle function in mice. Hum $\mathrm{Mol}$ Genet 2016;25:4328-4338.

30. Mateos-Aierdi AJ, Goicoechea M, Aiastui A, et al. Muscle wasting in myotonic dystrophies: a model of premature aging. Front Aging Neurosci 2015;7:1-16.

31. Labayru G, Diez I, Sepulcre J, et al. Regional brain atrophy in gray and white matter is associated with cognitive impairment in myotonic dystrophy type 1. Neuroimage Clin 2019;24:102078. doi: 10.1016/j.nicl.2019.102078. 


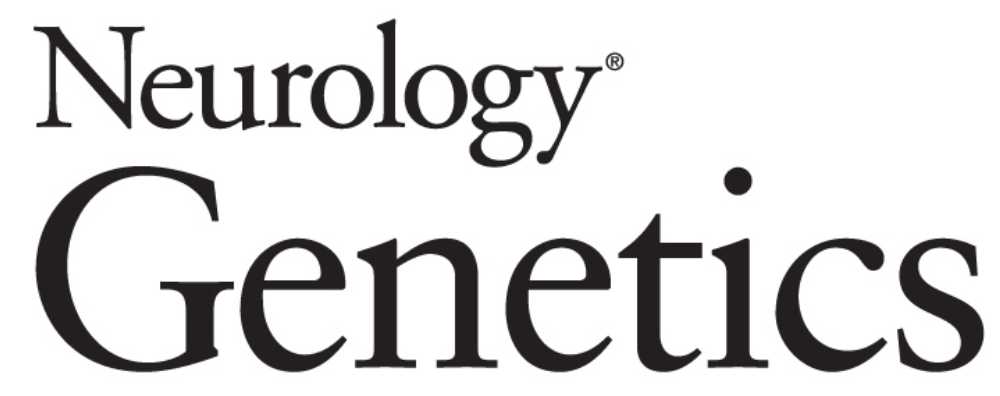

\section{DMPK mRNA Expression in Human Brain Tissue Throughout the Lifespan}

Kathleen E. Langbehn, Zoe Carlson-Stadler, Ellen van der Plas, et al. Neurol Genet 2021;7;

DOI 10.1212/NXG.0000000000000537

This information is current as of December 21, 2020

\section{Updated Information \&} Services

References

Subspecialty Collections

Permissions \& Licensing

Reprints including high resolution figures, can be found at: http://ng.neurology.org/content/7/1/e537.full.html

This article cites 25 articles, 0 of which you can access for free at: http://ng.neurology.org/content/7/1/e537.full.html\#\#ref-list-1

This article, along with others on similar topics, appears in the following collection(s):

Gene expression studies

http://ng.neurology.org//cgi/collection/gene_expression_studies Trinucleotide repeat diseases

http://ng.neurology.org//cgi/collection/trinucleotide_repeat_diseases

Information about reproducing this article in parts (figures,tables) or in its entirety can be found online at:

http://ng.neurology.org/misc/about.xhtml\#permissions

Information about ordering reprints can be found online: http://ng.neurology.org/misc/addir.xhtml\#reprintsus

Neurol Genet is an official journal of the American Academy of Neurology. Published since April 2015, it is an open-access, online-only, continuous publication journal. Copyright Copyright ( 2020 The Author(s). Published by Wolters Kluwer Health, Inc. on behalf of the American Academy of Neurology.. All rights reserved. Online ISSN: 2376-7839.

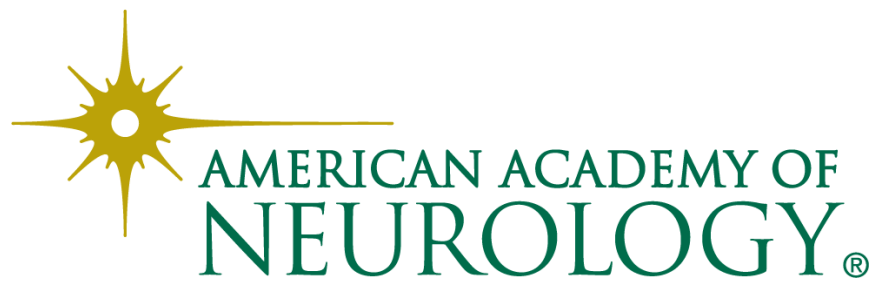

